\title{
Weak- and strong-convergence theorems of solutions to split feasibility problem for nonspreading type mapping in Hilbert spaces
}

Shih-sen Chang ${ }^{1}$, Jong Kyu Kim² ${ }^{2}$, Yeol Je Cho ${ }^{3}$ and Jae Yull Sim

"Correspondence:

jongkyuk@kyungnam.ac.kr

${ }^{2}$ Department of Mathematics

Education, Kyungnam University, Changwon, Gyeongnam 631-701

Korea

Full list of author information is

available at the end of the article

\begin{abstract}
The purpose of this article is to study the weak- and strong-convergence theorems of solutions to split a feasibility problem for a family of nonspreading-type mapping in Hilbert spaces. The main result presented in this paper improves and extends some recent results of Censor et al., Byrne, Yang, Moudafi, Xu, Censor and Segal, Masad and Reich, and others. As an application, we solve the hierarchical variational inequality problem by using the main theorem.

MSC: 47J05; 47H09; 49J25
\end{abstract}

Keywords: split feasibility problem; convex feasibility problem; $k$-strictly pseudo-nonspreading mapping; demicloseness; Opial's condition

\section{Introduction}

Throughout this paper, we assume that $H$ is a real Hilbert space, $D$ is a nonempty and closed convex subset of $H$. In the sequel, we denote by ' $x_{n} \rightarrow x^{\prime}$ ' and ' $x_{n} \rightarrow x$ ' the strong and weak convergence of $\left\{x_{n}\right\}$, respectively. Denote by $\mathcal{N}$ the set of all positive integers and by $F(T)$ the set of fixed points of a mapping $T: D \rightarrow D$.

Definition 1.1 Let $T: D \rightarrow D$ be a mapping.

(1) $T: D \rightarrow D$ is said to be nonexpansive if

$$
\|T x-T y\| \leq\|x-y\|, \quad \forall x, y \in D .
$$

(2) $T$ is said to be quasi-nonexpansive if $F(T)$ is nonempty and

$$
\|T x-p\| \leq\|x-p\|, \quad \forall x \in D, p \in F(T) .
$$

(3) $T$ is said to be nonspreading if

$$
2\|T x-T y\|^{2} \leq\|T x-y\|^{2}+\|T y-x\|^{2}, \quad \forall x, y \in D .
$$

It is easy to prove that equation (1.2) is equivalent to

$$
\|T x-T y\|^{2} \leq\|x-y\|^{2}+2\langle x-T x, y-T y\rangle, \quad \forall x, y \in D .
$$

\section{Springer}

O2014 Chang et al: licensee Springer. This is an Open Access article distributed under the terms of the Creative Commons Attribution License (http://creativecommons.org/licenses/by/2.0), which permits unrestricted use, distribution, and reproduction in any medium, provided the original work is properly cited. 
(4) $T$ is said to be $k$-strictly pseudo-nonspreading [1], if there exists a constant $k \in[0,1)$ such that

$$
\|T x-T y\|^{2} \leq\|x-y\|^{2}+k\|x-T x-(y-T y)\|^{2}+2\langle x-T x, y-T y\rangle, \quad \forall x, y \in D .
$$

Remark 1.2 It follows from Definition 1.1 that

(1) if $T$ is nonspreading and $F(T) \neq \emptyset$, then $T$ is quasi-nonexpansive;

(2) if $T$ is nonspreading, then it is $k$-strictly pseudo-nonspreading with $k=0$. But the converse is not true from the following example. Thus, we know that the class of $k$-strictly pseudo-nonspreading mappings is more general than the class of nonspreading mappings.

Example 1.3 [1] Let $\mathcal{R}$ denote the set of real numbers with the usual norm. Let $T: \mathcal{R} \rightarrow \mathcal{R}$ be a mapping defined by

$$
T x= \begin{cases}x, & x \in(-\infty, 0), \\ -2 x, & x \in[0, \infty) .\end{cases}
$$

Then $T$ is a $k$-strictly pseudo-nonspreading mapping, but it is not nonspreading.

In 2010, Kurokawa and Takahashi [2] obtained a weak mean ergodic theorem of Baillon's type [3] for nonspreading mappings in Hilbert spaces. They further proved a strongconvergence theorem somewhat related to Halpern's type [4] for this class of mappings using the idea of mean convergence in Hilbert spaces.

In 2011, Osilike and Isiogugu [1] first introduced the concept of $k$-strictly pseudononspreading mappings and proved a weak mean convergence theorem of Baillon's type similar to the ones obtained in [2]. Furthermore, using the idea of mean convergence, a strong-convergence theorem similar to the one obtained in [2] is proved which extends and improves the main theorems of [2] and an affirmative answer given to an open problem posed by Kurokawa and Takahashi [2] for the case where the mapping $T$ is averaged.

On the other hand, the split feasibility problem (SFP) in finitely dimensional spaces was first introduced by Censor and Elfving [5] for modeling inverse problems which arise from phase retrievals and in medical image reconstruction [6]. Recently, it has been found that the (SFP) can also be used in various disciplines such as image restoration, computer tomography and radiation therapy treatment planning [7-9].

The split feasibility problem in an infinitely dimensional Hilbert space can be found in $[6,8,10-12]$.

The purpose of this paper is to introduce the following multiple-set split feasibility problem (MSSFP) for an infinite family of $k$-strictly pseudo-nonspreading mappings and a finite family of $\rho$-strictly pseudo-nonspreading mappings in infinitely dimensional Hilbert spaces, i.e., to find $x^{*} \in C$ such that

$$
A x^{*} \in Q
$$

where $H_{1}, H_{2}$ are two real Hilbert spaces, $A: H_{1} \rightarrow H_{2}$ is a bounded linear operator, $\left\{S_{i}\right\}_{i=1}^{\infty}: H_{1} \rightarrow H_{1}$ is an infinite family of $k_{i}$-strictly pseudo-nonspreading mappings and 
$\left\{T_{i}\right\}_{i=1}^{N}: H_{2} \rightarrow H_{2}$ is a finite family of $\rho_{i}$-strictly pseudo-nonspreading mappings, $C:=$ $\bigcap_{i=1}^{\infty} F\left(S_{i}\right)$ and $Q:=\bigcap_{i=1}^{N} F\left(T_{i}\right)$. Also we wish to study the weak and strong convergence of the following iterative sequence to a solution of problem (1.6):

$$
\left\{\begin{array}{l}
x_{1} \in H_{1} \quad \text { chosen arbitrarily, } \\
x_{n+1}=\alpha_{0, n} y_{n}+\sum_{i=1}^{\infty} \alpha_{i, n} S_{i, \beta} y_{n}, \\
y_{n}=x_{n}+\gamma A^{*}\left(T_{n(\bmod N)}-I\right) A x_{n}, \quad \forall n \geq 1,
\end{array}\right.
$$

where $S_{i, \beta}:=\beta I+(1-\beta) S_{i}, \beta \in(0,1)$ is a constant.

In the sequel we denote $\Gamma$ the set of solutions of (MSSFP) equation (1.6), i.e.,

$$
\Gamma=\{x \in C, A x \in Q\}=C \cap A^{-1}(Q) .
$$

\section{Preliminaries}

For this purpose, we first recall some definitions, notations and conclusions which will be needed in proving our main results.

Definition 2.1 Let $E$ be a real Banach space, and $T: E \rightarrow E$ be a mapping.

(1) $I-T$ is said to be demiclosed at 0 , if, for any sequence $\left\{x_{n}\right\} \subset H$ with $x_{n} \rightarrow x^{*}$, $\left\|(I-T) x_{n}\right\| \rightarrow 0$, then $x^{*}=T x^{*}$.

(2) $T$ is said to be semicompact, if, for any bounded sequence $\left\{x_{n}\right\} \subset E$, $\lim _{n \rightarrow \infty}\left\|x_{n}-T x_{n}\right\|=0$, then there exists a subsequence $\left\{x_{n_{i}}\right\} \subset\left\{x_{n}\right\}$ such that $\left\{x_{n_{i}}\right\}$ converges strongly to some point $x^{*} \in E$.

Lemma 2.2 [1] Let $H$ be a real Hilbert space, $D$ be a nonempty and closed convex subset of $H$, and $T: D \rightarrow D$ be a $k$-strictly pseudo-nonspreading mapping.

(1) If $F(T) \neq \emptyset$, then $F(T)$ is closed and convex;

(2) $I-T$ is demiclosed at zero.

Lemma 2.3 Let $H$ be a real Hilbert space. Then the following statements hold:

(1) For all $x, y \in H$ and for all $t \in[0,1]$,

$$
\|t x+(1-t) y\|^{2}=t\|x\|^{2}+(1-t)\|y\|^{2}-t(1-t)\|x-y\|^{2} .
$$

(2) For all $x, y \in H$,

$$
\|x+y\|^{2} \leq\|x\|^{2}+2\langle y, x+y\rangle .
$$

Lemma 2.4 [13] Let E be a uniformly convex Banach space, $B_{r}(0):=\{x \in E:\|x\| \leq r\}$ be a closed ball with center 0 and radius $r>0$. Then for any given sequence $\left\{x_{1}, x_{2}, \ldots, x_{n}, \ldots\right\} \subset$ $B_{r}(0)$ and any given number sequence $\left\{\lambda_{1}, \lambda_{2}, \ldots, \lambda_{n}, \ldots\right\}$ with $\lambda_{i} \geq 0, \sum_{i=1}^{\infty} \lambda_{i}=1$, there exists a strictly increasing continuous and convex function $g:[0,2 r) \rightarrow[0, \infty)$ with $g(0)=0$ such that for any $i, j \in \mathcal{N}, i<j$,

$$
\left\|\sum_{n=1}^{\infty} \lambda_{n} x_{n}\right\|^{2} \leq \sum_{n=1}^{\infty} \lambda_{n}\left\|x_{n}\right\|^{2}-\lambda_{i} \lambda_{j} g\left(\left\|x_{i}-x_{j}\right\|\right) .
$$


Lemma 2.5 [10] Let $\left\{a_{n}\right\},\left\{b_{n}\right\}$ and $\left\{\delta_{n}\right\}$ be sequences of nonnegative real numbers satisfying

$$
a_{n+1} \leq\left(1+\delta_{n}\right) a_{n}+b_{n}, \quad \forall n \geq 1
$$

If $\sum_{i=1}^{\infty} \delta_{n}<\infty$ and $\sum_{i=1}^{\infty} b_{n}<\infty$, then the limit $\lim _{n \rightarrow \infty} a_{n}$ exists.

Lemma 2.6 Let $D$ be a nonempty and closed convex subset of $H$ and $T: D \rightarrow D$ be a $k$-strictly pseudo-nonspreading mapping with $F(T) \neq \emptyset$. Let $T_{\beta}=\beta I+(1-\beta) T, \beta \in[k, 1)$. Then the following conclusions hold:

(1) $F(T)=F\left(T_{\beta}\right)$;

(2) $I-T_{\beta}$ is demiclosed at zero;

(3) $\left\|T_{\beta} x-T_{\beta} y\right\|^{2} \leq\|x-y\|^{2}+\frac{2}{1-\beta}\left\langle x-T_{\beta} x, y-T_{\beta} y\right\rangle$;

(4) $T_{\beta}$ is a quasi-nonexpansive mapping.

Proof Since $\left(I-T_{\beta}\right)=(1-\beta)(I-T)$, the conclusions (1), (2) are obvious.

Now we prove the conclusion (3). In fact, since $T$ is a $k$-strictly pseudo-nonspreading mapping, it follows from Lemma 2.3 that

$$
\begin{aligned}
\left\|T_{\beta} x-T_{\beta} y\right\|^{2}= & \|\beta(x-y)+(1-\beta)(T x-T y)\|^{2} \\
= & \beta\|x-y\|^{2}+(1-\beta)\|T x-T y\|^{2} \\
& -\beta(1-\beta)\|x-T x-(y-T y)\|^{2} \\
\leq & \beta\|x-y\|^{2}+(1-\beta)\left\{\|x-y\|^{2}+k\|x-T x-(y-T y)\|^{2}\right. \\
& +2\langle x-T x, y-T y\rangle\}-\beta(1-\beta)\|x-T x-(y-T y)\|^{2} \\
= & \|x-y\|^{2}+2(1-\beta)\langle x-T x, y-T y\rangle \\
& -(1-\beta)(\beta-k)\|x-T x-(y-T y)\|^{2} \\
\leq & \|x-y\|^{2}+2(1-\beta)\langle x-T x, y-T y\rangle \\
= & \|x-y\|^{2}+\frac{2}{(1-\beta)}\left\langle x-T_{\beta} x, y-T_{\beta} y\right\rangle, \quad \forall x, y \in D .
\end{aligned}
$$

If $y \in F(T)$, then $y \in F\left(T_{\beta}\right)$. Hence from equation (2.4),

$$
\left\|T_{\beta} x-y\right\|=\left\|T_{\beta} x-T_{\beta} y\right\| \leq\|x-y\|, \quad \forall x \in D .
$$

This completes the proof of Lemma 2.6.

Lemma 2.7 [14] Let $H$ be a Hilbert space and $\left\{u_{n}\right\}$ be a sequence in $H$ such that there exists a nonempty set $W \subset H$ satisfying:

(1) for every $w \in W, \lim _{n \rightarrow \infty}\left\|u_{n}-w\right\|$ exists;

(2) each weak-cluster point of the sequence $\left\{w_{n}\right\}$ is in $W$.

Then there exists $w^{*} \in W$ such that $\left\{u_{n}\right\}$ weakly converges to $w^{*}$.

\section{Weak- and strong-convergence theorems}

For solving the multiple-set split feasibility problem (MSSFP) equation (1.6), we assume that the following conditions are satisfied: 
(1) $H_{1}$ and $H_{2}$ are two real Hilbert spaces, $A: H_{1} \rightarrow H_{2}$ is a bounded linear operator and $A^{*}: H_{2} \rightarrow H_{1}$ is the adjoint of $A$;

(2) $\left\{S_{i}\right\}_{i=1}^{\infty}: H_{1} \rightarrow H_{1}$ is an infinite family of $k_{i}$-strictly pseudo-nonspreading mappings with $k:=\sup _{i \geq 1} k_{i} \in(0,1)$;

(3) $\left\{T_{i}\right\}_{i=1}^{N}: H_{2} \rightarrow H_{2}$ is a finite family of $\rho_{i}$-strictly pseudo-nonspreading mappings with $\rho=\max \left\{\rho_{i}: i=1,2, \ldots, N\right\} \in(0,1)$;

(4) $C:=\bigcap_{i=1}^{\infty} F\left(S_{i}\right) \neq \emptyset$ and $Q:=\bigcap_{i=1}^{N} F\left(T_{i}\right) \neq \emptyset$.

Now we are in a position to give the following main theorem.

Theorem 3.1 Let $H_{1}, H_{2}, A, A^{*},\left\{S_{i}\right\}_{i=1}^{\infty},\left\{T_{i}\right\}_{i=1}^{N}, C, Q, k, \rho$ be the same as above. Let $\left\{x_{n}\right\}$ be a sequence generated by

$$
\left\{\begin{array}{l}
x_{1} \in H_{1} \quad \text { chosen arbitrarily, } \\
x_{n+1}=\alpha_{0, n} y_{n}+\sum_{i=1}^{\infty} \alpha_{i, n} S_{i, \beta} y_{n}, \quad \forall n \geq 1, \\
y_{n}=x_{n}+\gamma A^{*}\left(T_{n(\bmod N)}-I\right) A x_{n},
\end{array}\right.
$$

where $S_{i, \beta}:=\beta I+(1-\beta) S_{i}, i \geq 1, \beta \in[k, 1)$ is a constant, $\left\{\alpha_{i, n}\right\} \subset(0,1)$ and $\gamma>0$ satisfy the following conditions:

(a) $\sum_{i=0}^{\infty} \alpha_{i, n}=1$, for each $n \geq 1$;

(b) for each $i \geq 1, \liminf _{n \rightarrow \infty} \alpha_{0, n} \alpha_{i, n}>0$;

(c) $\gamma \in\left(0, \frac{1-\rho}{\|A\|^{2}}\right)$.

Let $\Gamma=\{x \in C, A x \in Q\} \neq \emptyset$ (the set of solutions of (MSSFP) equation (1.6) defined by equation (1.7)). Then we have the following:

(I) both $\left\{x_{n}\right\}$ and $\left\{y_{n}\right\}$ converge weakly to some point $x^{*} \in \Gamma$;

(II) in addition, if there exists some positive integer $m$ such that $S_{m}$ is semicompact, then both $\left\{x_{n}\right\}$ and $\left\{y_{n}\right\}$ converge strongly to $x^{*} \in \Gamma$.

Proof First we prove the conclusion (I).

Step 1. We prove that the sequences $\left\{x_{n}\right\},\left\{y_{n}\right\}$ and $\left\{S_{i, \beta} y_{n}\right\}$ are bounded and, for each $p \in \Gamma$, the following limits exist and

$$
\lim _{n \rightarrow \infty}\left\|x_{n}-p\right\|=\lim _{n \rightarrow \infty}\left\|y_{n}-p\right\|
$$

In fact, for given $p \in \Gamma$, by the definition of $\Gamma$,

$$
p \in C=\bigcap_{i=1}^{\infty} F\left(S_{i}\right)=\bigcap_{i=1}^{\infty} F\left(S_{i, \beta}\right)
$$

and

$$
A p \in Q:=\bigcap_{i=1}^{N} F\left(T_{i}\right) .
$$

Therefore, we have

$$
A p=T_{n(\bmod N)} A p .
$$


Since $\left\{S_{i}\right\}_{i=1}^{\infty}$ is a family of $k$-strictly pseudo-nonspreading mappings, by Lemma $2.2, C=$ $\bigcap_{i=1}^{\infty} F\left(S_{i}\right)$ is closed and convex. It follows from Lemma 2.6 that, for each $n \geq 1$ and $p \in \Gamma$,

$$
\begin{aligned}
\left\|x_{n+1}-p\right\| & =\left\|\alpha_{0, n}\left(y_{n}-p\right)+\sum_{i=1}^{\infty} \alpha_{i, n}\left(S_{i, \beta} y_{n}-p\right)\right\| \\
& \leq \alpha_{0, n}\left\|y_{n}-p\right\|+\sum_{i=1}^{\infty} \alpha_{i, n}\left\|S_{i, \beta} y_{n}-p\right\| \\
& =\left\|y_{n}-p\right\|, \\
\left\|y_{n}-p\right\|^{2} & =\left\|x_{n}-p+\gamma A^{*}\left(T_{n(\bmod N)}-I\right) A x_{n}\right\|^{2} \\
& =\left\|x_{n}-p\right\|^{2}+2 \gamma\left\langle x_{n}-p, A^{*}\left(T_{n(\bmod N)}-I\right) A x_{n}\right\rangle \\
& +\gamma^{2}\left\|A^{*}\left(T_{n(\bmod N)}-I\right) A x_{n}\right\|^{2}
\end{aligned}
$$

and

$$
\begin{aligned}
\gamma^{2}\left\|A^{*}\left(T_{n(\bmod N)}-I\right) A x_{n}\right\|^{2} & =\gamma^{2}\left\langle A^{*}\left(T_{n(\bmod N)}-I\right) A x_{n}, A^{*}\left(T_{n(\bmod N)}-I\right) A x_{n}\right\rangle \\
& =\gamma^{2}\left\langle A A^{*}\left(T_{n(\bmod N)}-I\right) A x_{n},\left(T_{n(\bmod N)}-I\right) A x_{n}\right\rangle \\
& \leq \gamma^{2}\|A\|^{2}\left\|\left(T_{n(\bmod N)}-I\right) A x_{n}\right\|^{2} .
\end{aligned}
$$

Further, since $\left\{T_{i}\right\}_{i=1}^{N}$ is a finite family of $\rho$-strictly pseudo-nonspreading mappings, we have

$$
\begin{aligned}
\left\langle x_{n}-\right. & \left.p, A^{*}\left(T_{n(\bmod N)}-I\right) A x_{n}\right\rangle \\
= & \left\langle A\left(x_{n}-p\right),\left(T_{n(\bmod N)}-I\right) A x_{n}\right\rangle \\
= & \left\langle A\left(x_{n}-p\right)+\left(T_{n(\bmod N)}-I\right) A x_{n}-\left(T_{n(\bmod N)}-I\right) A x_{n},\left(T_{n(\bmod N)}-I\right) A x_{n}\right\rangle \\
= & \left\langle T_{n(\bmod N)} A x_{n}-A p,\left(T_{n(\bmod N)}-I\right) A x_{n}\right\rangle-\left\|\left(T_{n(\bmod N)}-I\right) A x_{n}\right\|^{2} \\
= & \frac{1}{2}\left\{\left\|T_{n(\bmod N)} A x_{n}-A p\right\|^{2}+\left\|\left(T_{n(\bmod N)}-I\right) A x_{n}\right\|^{2}\right. \\
& \left.-\left\|A x_{n}-A p\right\|^{2}\right\}-\left\|\left(T_{n(\bmod N)}-I\right) A x_{n}\right\|^{2} \\
= & \frac{1}{2}\left\{\left\|T_{n(\bmod N)} A x_{n}-T_{n(\bmod N)} A p\right\|^{2}+\left\|\left(T_{n(\bmod N)}-I\right) A x_{n}\right\|^{2}\right. \\
& \left.-\left\|A x_{n}-A p\right\|^{2}\right\}-\left\|\left(T_{n(\bmod N)}-I\right) A x_{n}\right\|^{2} \\
\leq & \frac{1}{2}\left\{\left\|A x_{n}-A p\right\|^{2}+\rho\left\|\left(T_{n(\bmod N)}-I\right) A x_{n}\right\|^{2}\right\} \\
& +\frac{1}{2}\left\{\left\|\left(T_{n(\bmod N)}-I\right) A x_{n}\right\|^{2}-\left\|A x_{n}-A p\right\|^{2}\right\}-\left\|\left(T_{n(\bmod N)}-I\right) A x_{n}\right\|^{2} \\
= & \frac{\rho-1}{2}\left\|\left(T_{n(\bmod N)}-I\right) A x_{n}\right\|^{2} .
\end{aligned}
$$

Substituting equations (3.5) and (3.6) into equation (3.4) and simplifying, we have

$$
\left\|y_{n}-p\right\|^{2} \leq\left\|x_{n}-p\right\|^{2}-\gamma\left(1-\rho-\gamma\|A\|^{2}\right)\left\|\left(T_{n(\bmod N)}-I\right) A x_{n}\right\|^{2} .
$$


By condition (c), $\left(1-\rho-\gamma\|A\|^{2}\right)>0$, therefore we have

$$
\left\|y_{n}-p\right\|^{2} \leq\left\|x_{n}-p\right\|^{2}
$$

Substituting equation (3.8) into equation (3.3), we have

$$
\left\|x_{n+1}-p\right\| \leq\left\|x_{n}-p\right\|, \quad \forall n \geq 1 .
$$

This implies that the $\operatorname{limit} \lim _{n \rightarrow \infty}\left\|x_{n}-p\right\|$ exists. It follows from equations (3.8) and (3.3)

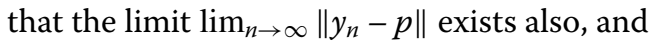

$$
\lim _{n \rightarrow \infty}\left\|x_{n}-p\right\|=\lim _{n \rightarrow \infty}\left\|y_{n}-p\right\|, \quad \forall p \in \Gamma .
$$

Therefore, $\left\{x_{n}\right\}$ and $\left\{y_{n}\right\}$ are bounded. Since for each $i \geq 1, S_{i, \beta}$ is quasi-nonexpansive, we have

$$
\left\|S_{i, \beta} y_{n}-p\right\| \leq\left\|y_{n}-p\right\| .
$$

Hence $\left\{S_{i, \beta} y_{n}\right\}$ is also bounded.

Step 2 . Now we prove that for any given positive integer $l \geq 1$, the following conclusions hold:

$$
\lim _{n \rightarrow \infty}\left\|y_{n}-S_{l, \beta} y_{n}\right\|=0 ; \quad \lim _{n \rightarrow \infty}\left\|T_{n(\bmod N)} A x_{n}-A x_{n}\right\|=0 .
$$

In fact, for any given $p \in \Gamma$, it follows from equation (3.1), Lemma 2.4, and equation (3.7) that

$$
\begin{aligned}
\left\|x_{n+1}-p\right\|^{2}= & \left\|\alpha_{0, n}\left(y_{n}-p\right)+\sum_{i=1}^{\infty} \alpha_{i, n}\left(S_{i, \beta} y_{n}-p\right)\right\|^{2} \\
\leq & \alpha_{0, n}\left\|y_{n}-p\right\|^{2}+\sum_{i=1}^{\infty} \alpha_{i, n}\left\|S_{i, \beta} y_{n}-p\right\|^{2}-\alpha_{0, n} \alpha_{l, n} g\left(\left\|y_{n}-S_{i, \beta} y_{n}\right\|\right) \\
\leq & \alpha_{0, n}\left\|y_{n}-p\right\|^{2}+\sum_{i=1}^{\infty} \alpha_{i, n}\left\|y_{n}-p\right\|^{2}-\alpha_{0, n} \alpha_{l, n} g\left(\left\|y_{n}-S_{i, \beta} y_{n}\right\|\right) \\
= & \left\|y_{n}-p\right\|^{2}-\alpha_{0, n} \alpha_{l, n} g\left(\left\|y_{n}-S_{i, \beta} y_{n}\right\|\right) \\
\leq & \left\|x_{n}-p\right\|^{2}-\gamma\left(1-\rho-\gamma\|A\|^{2}\right)\left\|\left(T_{n(\bmod N)}-I\right) A x_{n}\right\|^{2} \\
& -\alpha_{0, n} \alpha_{l, n} g\left(\left\|y_{n}-S_{i, \beta} y_{n}\right\|\right), \quad n \geq 1 .
\end{aligned}
$$

Therefore, we have

$$
\begin{aligned}
& \gamma\left(1-\rho-\gamma\|A\|^{2}\right)\left\|\left(T_{n(\bmod N)}-I\right) A x_{n}\right\|^{2}+\alpha_{0, n} \alpha_{l, n} g\left(\left\|y_{n}-S_{l, \beta} y_{n}\right\|\right) \\
& \quad \leq\left\|x_{n}-p\right\|^{2}-\left\|x_{n+1}-p\right\|^{2} \\
& \quad \rightarrow 0 \quad(\text { as } n \rightarrow \infty) .
\end{aligned}
$$


By conditions (b) and (c) we have

$$
\lim _{n \rightarrow \infty}\left\|\left(T_{n(\bmod N)}-I\right) A x_{n}\right\|=0 ; \quad \lim _{n \rightarrow \infty} g\left(\left\|y_{n}-S_{l, \beta} y_{n}\right\|\right)=0 .
$$

Since $g$ is continuous and strictly increasing with $g(0)=0$, from equation (3.12) we have

$$
\lim _{n \rightarrow \infty}\left\|y_{n}-S_{l, \beta} y_{n}\right\|=0 \quad \text { for each } l \geq 1 .
$$

Hence conclusion (3.10) is proved.

Step 3. Now, we prove that

$$
\lim _{n \rightarrow \infty}\left\|x_{n+1}-x_{n}\right\|=0 ; \quad \lim _{n \rightarrow \infty}\left\|y_{n+1}-y_{n}\right\|=0 .
$$

In fact, it follows from equation (3.1) that

$$
\begin{aligned}
\left\|x_{n+1}-x_{n}\right\|^{2}= & \left\|\alpha_{0, n}\left(y_{n}-x_{n}\right)+\sum_{i=1}^{\infty} \alpha_{i, n}\left(S_{i, \beta} y_{n}-x_{n}\right)\right\|^{2} \\
= & \left\|\alpha_{0, n}\left(\gamma A^{*}\left(T_{n(\bmod N)}-I\right) A x_{n}\right)+\sum_{i=1}^{\infty} \alpha_{i, n}\left(S_{i, \beta} y_{n}-x_{n}\right)\right\|^{2} \\
\leq & \alpha_{0, n}\left\|\gamma A^{*}\left(T_{n(\bmod N)}-I\right) A x_{n}\right\|^{2}+\sum_{i=1}^{\infty} \alpha_{i, n}\left\|S_{i, \beta} y_{n}-x_{n}\right\|^{2} \\
\leq & \alpha_{0, n}\left\|\gamma A^{*}\left(T_{n(\bmod N)}-I\right) A x_{n}\right\|^{2} \\
& +\sum_{i=1}^{\infty} \alpha_{i, n}\left(\left\|S_{i, \beta} y_{n}-y_{n}\right\|+\left\|y_{n}-x_{n}\right\|\right)^{2} .
\end{aligned}
$$

By virtue of equations (3.1) and (3.10), one has

$$
\begin{aligned}
\left\|y_{n}-x_{n}\right\| & =\gamma\left\|A^{*}\left(T_{n(\bmod N)}-I\right) A x_{n}\right\| \\
& \rightarrow 0 \quad(\text { as } n \rightarrow \infty) .
\end{aligned}
$$

This together with equations (3.10) and (3.15) shows that

$$
\left\|x_{n+1}-x_{n}\right\| \rightarrow 0 \quad(\text { as } n \rightarrow \infty) .
$$

Similarly, we have

$$
\begin{aligned}
\left\|y_{n+1}-y_{n}\right\|= & \| x_{n+1}+\gamma A^{*}\left(T_{(n+1)(\bmod N)}-I\right) A x_{n+1} \\
& -\left[x_{n}+\gamma A^{*}\left(T_{n(\bmod N)}-I\right) A x_{n}\right] \| \\
\leq & \left\|x_{n+1}-x_{n}\right\|+\gamma\left\|A^{*}\left(T_{(n+1)(\bmod N)}-I\right) A x_{n+1}\right\| \\
& +\gamma\left\|A^{*}\left(T_{n(\bmod N)}-I\right) A x_{n}\right\| \\
\rightarrow & 0 \quad(\operatorname{as} n \rightarrow \infty) .
\end{aligned}
$$


Step 4 . Now we show that every weak-cluster point $x^{*}$ of the sequence $\left\{x_{n}\right\}$ is in $\Gamma$.

Indeed, since $\left\{y_{n}\right\}$ is a bounded sequence in $H_{1}$, there exists a subsequence $\left\{y_{n_{i}}\right\} \subset\left\{y_{n}\right\}$ such that $y_{n_{i}} \rightarrow x^{*} \in H_{1}$. It follows from equation (3.10) that

$$
\lim _{n \rightarrow \infty}\left\|y_{n_{i}}-S_{l, \beta} y_{n_{i}}\right\|=0 \quad \text { for each } l \geq 1 .
$$

By Lemma 2.2, $\left(I-S_{i}\right)$ is demiclosed at zero. Since $\left(I-S_{l, \beta}\right)=(1-\beta)\left(I-S_{i}\right)$, this implies that $\left(I-S_{l, \beta}\right)$ is also demiclosed at zero. Hence $x^{*} \in F\left(S_{l, \beta}\right)=F\left(S_{l}\right)$. By the arbitrariness of $l \geq 1$, we have

$$
x^{*} \in \bigcap_{i=1}^{\infty} F\left(S_{i}\right)=C
$$

On the other hand, it follows from equations (3.1) and (3.10) that

$$
x_{n_{i}}=y_{n_{i}}-\gamma A^{*}\left(T_{n_{i}(\bmod N)}-I\right) A x_{n_{i}}-x^{*} .
$$

Since $A$ is a bounded linear operator, this implies that $A x_{n_{i}} \rightarrow A x^{*}$. Also, by equation (3.10)

$$
\lim _{n_{i} \rightarrow \infty}\left\|T_{n_{i}(\bmod N)} A x_{n_{i}}-A x_{n_{i}}\right\|=0 .
$$

Hence for any given positive integer $j=1,2, \ldots, N$, there exists a subsequence $\left\{n_{i_{k}}\right\} \subset\left\{n_{i}\right\}$ with $n_{i_{k}}(\bmod N)=j$ such that

$$
\lim _{n_{i_{k}} \rightarrow \infty}\left\|T_{j} A x_{n_{i_{k}}}-A x_{n_{i_{k}}}\right\|=0
$$

Since $A x_{n_{i_{k}}} \rightarrow A x^{*}$, and by Lemma 2.2, $I-T_{j}$ is demiclosed at 0 . This implies that $A x^{*} \in F\left(T_{j}\right)$. By the arbitrariness of $j=1,2, \ldots, N$,

$$
A x^{*} \in \bigcap_{j=1}^{N} F\left(T_{j}\right)=Q .
$$

These show that $x^{*} \in \Gamma$.

Step 5. Summing up the above arguments, we have proved that: (i) for each $p \in \Gamma$, the limits $\lim _{n \rightarrow \infty}\left\|x_{n}-p\right\|$ and $\lim _{n \rightarrow \infty}\left\|y_{n}-p\right\|$ exist (see equation (3.2)); (ii) every weakcluster point $x^{*}$ of the sequence $\left\{x_{n}\right\}$ (or $\left.\left\{y_{n}\right\}\right)$ is in $\Gamma$. Taking $W=\Gamma$ and $\left\{u_{n}\right\}=\left\{x_{n}\right\}$ (or $\left.\left\{y_{n}\right\}\right)$ in Lemma 2.7, therefore all conditions in Lemma 2.7 are satisfied. By using Lemma 2.7, $x_{n} \rightarrow x^{*}, y_{n} \rightarrow x^{*}$ and $x^{*} \in \Gamma$. This completes the proof of the conclusion (I).

Next we prove the conclusion (II).

Without loss of generality, we may assume that $S_{1}$ is semicompact. Since $\left(I-S_{1, \beta}\right)=$ $(1-\beta)\left(I-S_{1}\right)$, this implies that $S_{1, \beta}$ is also semicompact. In view of equation (3.10), we have

$$
\left\|y_{n}-S_{1, \beta} y_{n}\right\| \rightarrow 0 \quad(\text { as } n \rightarrow \infty) .
$$


Therefore, there exists a subsequence of $\left\{y_{n_{i}}\right\} \subset\left\{y_{n}\right\}$ such that $y_{n_{i}} \rightarrow u^{*} \in H_{1}$. Since $y_{n_{i}} \rightarrow$ $x^{*}$, we have $x^{*}=u^{*}$ and so $y_{n_{i}} \rightarrow x^{*} \in \Gamma$. By virtue of equation (3.9), we have

$$
\lim _{n \rightarrow \infty}\left\|y_{n}-x^{*}\right\|=0, \quad \lim _{n \rightarrow \infty}\left\|x_{n}-x^{*}\right\|=0,
$$

i.e., $\left\{y_{n}\right\}$ and $\left\{x_{n}\right\}$ both converge strongly to the point $x^{*} \in \Gamma$. This completes the proof of Theorem 3.1.

Remark 3.2 Theorem 3.1 improves and extends the corresponding results of Censor et al. [5, 8, 9], Byrne [6], Yang [11], Moudafi [15], Xu [16], Censor and Segal [17], Masad and Reich [18], Deepho and Kumam [19, 20] and others in the following aspects:

(a) for the mappings, we extend the mappings from nonexpansive mappings, or demi-contractive mappings, to the more general family of $k$-strictly pseudo-nonspreading mappings;

(b) for the algorithms, we propose some new hybrid iterative algorithms which are different from the ones given in $[5-7,9,17,18,21,22]$. Under suitable conditions, some weak- and strong-convergence results for the algorithms are proved.

If we put $\gamma=0$ in Theorem 3.1, we immediately get the following.

Corollary 3.3 Let $H,\left\{S_{i}\right\}_{i=1}^{\infty}$, k be the same as above. Let $\left\{x_{n}\right\}$ be a sequence generated by

$$
\left\{\begin{array}{l}
x_{1} \in H \quad \text { chosen arbitrarily, } \\
x_{n+1}=\alpha_{0, n} x_{n}+\sum_{i=1}^{\infty} \alpha_{i, n} S_{i, \beta} x_{n},
\end{array} \quad \forall n \geq 1,\right.
$$

where $S_{i, \beta}:=\beta I+(1-\beta) S_{i}, i \geq 1, \beta \in[k, 1)$ is a constant, $\left\{\alpha_{i, n}\right\} \subset(0,1)$ satisfy the following conditions:

(a) $\sum_{i=0}^{\infty} \alpha_{i, n}=1$, for each $n \geq 1$;

(b) for each $i \geq 1, \liminf _{n \rightarrow \infty} \alpha_{0, n} \alpha_{i, n}>0$. Let

$$
\mathcal{F}:=\bigcap_{i=1}^{\infty} F\left(S_{i}\right) \neq \emptyset .
$$

Then we have the following:

(I) the sequence $\left\{x_{n}\right\}$ converges weakly to some point $x^{*} \in \mathcal{F}$;

(II) in addition, if there exists some positive integer $m$ such that $S_{m}$ is semicompact, then the sequence $\left\{x_{n}\right\}$ converges strongly to $x^{*} \in \mathcal{F}$.

\section{Applications}

In this section we utilize the results presented in Section 3 to study the hierarchical variational inequality problem.

Let $H$ be a real Hilbert space, $\left\{S_{i}\right\}: H \rightarrow H, i=1,2, \ldots$ be a countable family of $k_{i}$-strictly pseudo-nonspreading mappings with $k=\sup _{i \geq 1} k_{i} \in(0,1)$, and

$$
\mathcal{F}:=\bigcap_{i=1}^{\infty} F\left(S_{i}\right) \neq \emptyset .
$$


Let $T: H \rightarrow H$ be a nonspreading mapping. The so-called hierarchical variational inequality problem for a countable family of mappings $\left\{S_{i}\right\}$ with respect to mapping $T$ is to find an $x^{*} \in \mathcal{F}$ such that

$$
\left\langle x^{*}-T x^{*}, x^{*}-x\right\rangle \leq 0, \quad \forall x \in \mathcal{F} .
$$

It is easy to see that equation (4.1) is equivalent to the following fixed point problem: to find $x^{*} \in \mathcal{F}$ such that

$$
x^{*}=P_{\mathcal{F}} T x^{*},
$$

where $P_{\mathcal{F}}$ is the metric projection from $H$ onto $\mathcal{F}$. Letting $C=\mathcal{F}$ and $Q=F\left(P_{\mathcal{F}} T\right)$ (the fixed point set of $P_{\mathcal{F}} T$ ) and $A=I$ (the identity mapping on $H$ ), then the problem (4.2) is equivalent to the following multi-set split feasibility problem: to find $x^{*} \in C$ such that

$$
x^{*} \in Q \text {. }
$$

Hence from Theorem 3.1 we have the following theorem.

Theorem 4.1 Let $H,\left\{S_{i}\right\}, T, C, Q, k$ be the same as above. Let $\left\{x_{n}\right\},\left\{y_{n}\right\}$ be the sequences defined by

$$
\left\{\begin{array}{l}
x_{1} \in H_{1} \quad \text { chosen arbitrarily, } \\
x_{n+1}=\alpha_{0, n} y_{n}+\sum_{i=1}^{\infty} \alpha_{i, n} S_{i, \beta} y_{n}, \\
y_{n}=x_{n}+\gamma(T-I) x_{n}, \quad \forall n \geq 1,
\end{array}\right.
$$

where $S_{i, \beta}:=\beta I+(1-\beta) S_{i}, i \geq 1, \beta \in[k, 1),\left\{\alpha_{i, n}\right\} \subset(0,1)$ and $\gamma>0$ satisfy the following conditions:

(a) $\sum_{i=0}^{\infty} \alpha_{i, n}=1$, for each $n \geq 1$;

(b) for each $i \geq 1$, $\liminf _{n \rightarrow \infty} \alpha_{0, n} \alpha_{i, n}>0$;

(c) $\gamma \in(0,1)$.

If $C \cap Q \neq \emptyset$, then $\left\{x_{n}\right\}$ converges weakly to a solution of the hierarchical variational inequality problem (4.1). In addition, if one of the mappings $S_{i}$ is semicompact, then both $\left\{x_{n}\right\}$ and $\left\{y_{n}\right\}$ converge strongly to a solution of the hierarchical variational inequality problem (4.1).

Proof In fact, by the assumption that $T$ is a nonspreading mapping, hence by Remark 1.2, $T$ is a $\rho$-strictly pseudo-nonspreading with $\rho=0$. Taking $N=1$ and $A=I$ in Theorem 3.1, all conditions in Theorem 3.1 are satisfied. The conclusions of Theorem 4.1 can immediately be obtained from Theorem 3.1 .

Remark 4.2 If $T=I$ (the identity mapping), then we can get the results of Corollary 3.3. 


\section{Author details}

${ }^{1}$ College of Statistics and Mathematics, Yunnan University of Finance and Economics, Kunming, Yunnan 650221, China.

${ }^{2}$ Department of Mathematics Education, Kyungnam University, Changwon, Gyeongnam 631-701, Korea. ${ }^{3}$ Department of Mathematics Education and the RINS, Gyeongsang National University, Chinju, 660-701, Korea. ${ }^{4}$ Department of Mathematics, Kyungnam University, Changwon, Gyeongnam 631-701, Korea.

\section{Acknowledgements}

This work was supported by the Basic Science Research Program through the National Research Foundation (NRF) Grant funded by Ministry of Education of the republic of Korea (2013R1A1A2054617).

\section{Received: 1 October 2013 Accepted: 17 December 2013 Published: 09 Jan 2014}

\section{References}

1. Osilike, MO, Isiogugu, FO: Weak and strong convergence theorems for nonspreading-type mappings in Hilbert spaces. Nonlinear Anal. 74, 1814-1822 (2011)

2. Kurokawa, Y, Takahashi, W: Weak and strong convergence theorems for nonspreading mappings in Hilbert spaces. Nonlinear Anal. 73, 1562-1568 (2010)

3. Baillon, J: Un theorem de type ergodique pour les contractions nonlineaires dans un espace de Hilbert. C. R. Acad. Sci., Ser. A-B 280(Aii), A1511-A1514 (1975)

4. Halpern, B: Fixed points of nonexpanding mappings. Bull. Am. Math. Soc. 73, 957-961 (1967)

5. Censor, Y, Elfving, T: A multi-projection algorithm using Bregman projections in a product space. Numer. Algorithms 8, 221-239 (1994)

6. Byrne, C: Iterative oblique projection onto convex subsets and the split feasibility problem. Inverse Probl. 18, 441-453 (2002)

7. Censor, Y, Bortfeld, T, Martin, B, Trofimov, A: A unified approach for inversion problem in intensity-modulated radiation therapy. Phys. Med. Biol. 51, 2353-2365 (2006)

8. Censor, Y, Elfving, T, Kopf, N, Bortfeld, T: The multiple-sets split feasibility problem and its applications. Inverse Probl. 21, 2071-2084 (2005)

9. Censor, Y, Motova, A, Segal, A: Perturbed projections and subgradient projections for the multiple-sets split feasibility problem. J. Math. Anal. Appl. 327, 1244-1256 (2007)

10. Xu, HK: A variable Krasnosel'skii-Mann algorithm and the multiple-sets split feasibility problem. Inverse Probl. 22 2021-2034 (2006)

11. Yang, Q: The relaxed CQ algorithm for solving the split feasibility problem. Inverse Probl. 20, 1261-1266 (2004)

12. Zhao, J, Yang, Q: Several solution methods for the split feasibility problem. Inverse Probl. 21, 1791-1799 (2005)

13. Chang, SS, Kim, JK, Wang, XR: Modified block iterative algorithm for solving convex feasibility problems in Banach spaces. J. Inequal. Appl. 2010, Article ID 869684 (2010). doi:10.1155/2010/869684

14. Moudafi, A, Al-Shemas, E: Simultaneous iterative methods for split equality problem. Trans. Math. Program. Appl. 1, 1-11 (2013)

15. Moudafi, A: The split common fixed point problem for demi-contractive mappings. Inverse Probl. 26, 055007 (2010)

16. Xu, HK: Iterative methods for split feasibility problem in infinite-dimensional Hilbert spaces. Inverse Probl. 26, 105018 (2010)

17. Censor, Y, Segal, A: The split common fixed point problem for directed operators. J. Convex Anal. 16, 587-600 (2009)

18. Masad, E, Reich, S: A note on the multiple-set split feasibility problem in Hilbert spaces. J. Nonlinear Convex Anal. 8 , 367-371 (2007)

19. Deepho, J, Kumam, P: Split feasibility and fixed-point problems for asymptotically quasi-nonexpansive mappings. J. Inequal. Appl. 2013, 322 (2013). doi:10.1186/1029-242X-2013-322

20. Deepho, J, Kumam, P: A modified Halpern's iterative scheme for solving split feasibility problems. Abstr. Appl. Anal. 2012, Article ID 876069 (2012)

21. Yang, L, Chang, SS, Cho, YJ, Kim, JK: Multiple-set split feasibility problems for total asymptotically strict pseudocontraction mappings. Fixed Point Theory Appl. 2011, 77 (2011). doi:10.1186/1687-1812-2011-77

22. Chang, SS, Cho, YJ, Kim, JK, Zhang, WB, Yang, L: Multiple-set split feasibility problems for asymptotically strict pseudocontractions. Abstr. Appl. Anal. 2012, Article ID 491760 (2012). doi:10.1155/2012/491760

10.1186/1687-1812-2014-11

Cite this article as: Chang et al.: Weak- and strong-convergence theorems of solutions to split feasibility problem for nonspreading type mapping in Hilbert spaces. Fixed Point Theory and Applications 2014, $2014: 11$ 